\title{
FELIZ ANIVERSÁRIO(S): A INFLUÊNCIA NO COMPORTAMENTO DAS CONSUMIDORAS MÃES NA REALIZAÇÃO DOS MESVERSÁRIOS
}

\author{
Rayane Evelyn Vasconcelos Saturnino, Centro Universitário de João Pessoa - UNIPÊ \\ rayevelyn12@gmail.com \\ Janayna Souto Leal, Universidade Federal da Paraíba - UFPB \\ leal.janayna@gmail.com \\ João Batista Soares Neto, Universidade Federal da Paraíba - UFPB \\ inetojp@gmail.com
}

\section{RESUMO}

Evento cada vez mais adotado para comemorar os meses de vida das crianças e que tem motivado o mercado de festas infantis, o mesversário tem sido alvo de influências no processo de tomada de decisão das mães. Logo, este estudo objetivou analisar os fatores que influenciam as mães na realização dos mesversários. Metodologicamente, a pesquisa adotou uma abordagem qualitativa e a coleta de dados foi feita mediante entrevistas com 21 mães. O método escolhido foi a análise de conteúdo e as categorias analisadas foram: Processo decisório; Comportamento de consumo das mães; Influências internas e externas. Os resultados evidenciaram que as mães sofrem influências internas e externas, cuja família é a principal influenciadora nas decisões da mãe. Concluindo, nota-se que, apesar dessa influência, as mães promovem os mesversários como forma de celebrar a vida da criança e para estabelecer/fortalecer um vínculo com as pessoas que fazem parte da vida do bebê.

Palavras-chave: Influências, Comportamento do consumidor, Mesversários.

Data de recebimento: $26 / 07 / 2020$

Data do aceite de publicação: 01/12/2020

Data da publicação: $30 / 12 / 2020$ 


\title{
HAPPY BIRTHDAY (S): THE INFLUENCE ON THE BEHAVIOR OF MOTHER CONSUMERS IN THE PERFORMANCE OF MESVERSARIES
}

\author{
Rayane Evelyn Vasconcelos Saturnino, Centro Universitário de João Pessoa - UNIPÊ \\ rayevelyn12@gmail.com \\ Janayna Souto Leal, Universidade Federal da Paraíba - UFPB \\ leal.janayna@gmail.com \\ João Batista Soares Neto, Universidade Federal da Paraíba - UFPB \\ jnetojp@gmail.com
}

\begin{abstract}
An event increasingly adopted to celebrate the children's months of life and which has motivated the children's parties market, the mesversário has been the target of influences on the mothers' decision-making process. Therefore, this study aimed to analyze the factors that influence mothers in the performance of mesversários. Methodologically, the research adopted a qualitative approach and data collection was carried out through interviews with 21 mothers. The method chosen was content analysis and the categories analyzed were: Decision-making process; Mothers' consumption behavior; Internal and external influences. The results showed that mothers suffer internal and external influences, whose family is the main influence on the mother's decisions. In conclusion, it is noted that, despite this influence, mothers promote mesversários as a way to celebrate the child's life and to establish/strengthen a bond with the people who are part of the baby's life.
\end{abstract}

Keywords: Influences, Consumer behavior, Mesversários.

\section{INTRODUÇÃO}

Em um mercado altamente competitivo e tecnológico, em que a personalização ganha cada vez mais representatividade, percebe-se que, na configuração atual, organizações e pessoas buscam inovação e diferenciação na procura de um bem e/ou serviço. Nesse sentido, o Marketing tem sido um recurso cada vez mais explorado no intuito de estimular e alavancar a imagem de variados produtos e também de diversas experiências, o que, consequentemente, acaba por refletir na aceitação ou na rejeição de uma ideia, a depender do modo de como ela foi criada e disseminada para o mercado.

Em paralelo, destaca-se o poder de influência que as ferramentas do Marketing podem proporcionar no que tange a oferta e demanda. Em um cenário permeado por transformações e por uma comunicação ágil e veloz, os consumidores são constantemente confrontados por novidades e tendências, o que pode acarretar em repetidas mudanças de opinião e, ao mesmo tempo, de adesão pelo o que é novo e pelo o que agrada a um conjunto considerável de pessoas.

Logo, as pessoas possuem uma probabilidade de inclinação na escolha de algum produto ou serviço quando gostam da sua imagem, de uma maneira geral, e também porque acreditam que a sua personalidade corresponda e se conecte com o que está 


\section{FELIZ ANIVERSÁRIO(S): A INFLUÊNCIA NO COMPORTAMENTO DAS CONSUMIDORAS MÃES NA REALIZAÇÃO DOS MESVERSÁRIOS}

sendo ofertado Solomon (2016). Em outras palavras, diversos aspectos que o produto ou serviço carrega em si acaba por influenciar, de alguma maneira, o consumidor.

A relação entre o indivíduo e o produto/serviço é bastante distinta, variando a cada pessoa e em como os seus desejos e necessidades são satisfeitos. Diferentes aspectos como grupos, fatores, ambientais, entre outros, devem ser levados em consideração. Para tanto, tais situações são avaliadas mediante o estudo do comportamento do consumidor. De acordo com Solomon (2016), esta é uma área extensa de pesquisa, mas que pode ser definida como o estudo dos processos envolvidos quando pessoas ou grupos selecionam, compram, usam ou descartam produtos, serviços, ideias ou experiências para satisfazer as suas necessidades ou desejos.

Em meio a esta perspectiva, um evento que surgiu de maneira tímida, mas que se difundiu rapidamente, muito em função das mídias sociais, é o do mesversário. Tradicionalmente, o primeiro aniversário sempre foi comemorado quando a criança chegava a um ano de idade. Porém, devido a ansiedade, alguns pais, com destaque para a figura da mãe, não conseguiram esperar tantos meses e começaram a comemorar a vida dos filhos nos meses antecedentes a "grande data". Inicialmente, a ideia surgiu com a realização de um lanche pequeno, com um bolo recheado, e registros fotográficos da criança junto aos seus familiares. Contudo, as celebrações passaram a ficar cada vez mais trabalhadas, os bolos passaram a ser maiores, temáticos e encomendados por profissionais, ficando mais caros e vistosos, transformando, muitas vezes, uma comemoração parental em eventos grandiosos (LIMA, 2019).

Partindo desse princípio, o presente trabalho traz o seguinte problema de pesquisa: Qual (is) fator (es) influenciam as consumidoras mães na realização dos mesversários? Com base nisso, ele tem como objetivo geral analisar qual(is) fator(es) influenciam as consumidoras mães na realização dos mesversários e possui os seguintes objetivos específicos: Identificar as influências internas e externas no comportamento de compra das consumidoras mães; Verificar como acontece o processo decisório de adesão a prática do(s) mesversário(s); Examinar a relação entre as influências e a realização do(s) mesversário(s).

Como justificativa para este estudo, alguns dados sinalizam a relevância deste tema para o mercado. Segundo dados divulgados pela Associação Brasileira de Eventos (ABRAFESTA, 2016), as mamães não têm poupado quando o assunto é comemorar o mês-a-mês dos seus bebês visto que festa infantil é um mercado em alta com um faturamento em torno de $\mathrm{R} \$ 16,8$ bilhões anual, número que também se estende aos chás de revelação e de bebê, batizados e mesversários.

Além disso, decidiu-se por essa temática devido à notória e crescente popularização desse nicho de mercado, o que já foi relatado por autores e portal de notícia neste mesmo trabalho. A prática do mesversário vem trazendo um movimento positivo no comércio, em que muitas empresas têm conseguido diversificar os seus ganhos, haja visto o caráter contínuo desse tipo de evento. Tal cultura vem se disseminando rapidamente, visto que, gradativamente, este ritual vem envolvendo muito mais do que uma simples comemoração, registros fotográficos, bolo, decoração, roupas, entre outros itens, acabam por se tornar relevantes, o que pode impactar no comportamento das consumidoras mães (LIMA, 2019).

A seguir, os capítulos deste trabalho terão como composição o referencial teórico, os procedimentos metodológicos, a análise dos resultados e, por fim, as considerações finais. 


\section{REFERENCIAL TEÓRICO}

Neste capítulo serão abordados pontos específicos com a intenção de elucidar as influências que impactam no comportamento das consumidoras mães na realização dos eventos infantis dos mesversários. Para tanto, serão analisados tópicos sobre marketing; comportamento do consumidor; as suas influências; e por fim, o fenômeno dos mesversários.

\subsection{Comportamento do consumidor}

O comportamento do consumidor, para Schiffman e Kanuk (2015), é diagnosticado conforme a procura na compra, na utilização, na avaliação, e na destinação dos produtos e serviços para atender às suas necessidades e desejos. $\mathrm{Na}$ contemporaneidade, os consumidores podem fazer suas compras de maneira offline (física) como on-line (no ambiente digital) de diversos produtos.

Sob essa perspectiva, o comportamento do consumidor é discutido de diversas maneiras, pois nos dias atuais o consumo tem virado um hábito mais forte e presente na realidade de muitos. Esse comportamento está ligado a obter, consumir e dispor de produtos e serviços, incluindo tudo o que ocorre antes e após a aquisição do produto/serviço (ENGEL; BLACKWELL; MINIARD, 2000).

De acordo com os autores, percebe-se que o consumidor assume o protagonismo na relação com a organização, ditando as regras para uma melhor convivência. Os objetivos e a aceitação dos produtos/serviços irão depender do quanto as empresas serão capazes de se aproximar do que os consumidores, de fato, desejam ou necessitam. Para tanto, elas tentam investigar, estudar e conhecer o seu público-alvo de modo que possam ser mais assertivos e conquistem as suas respectivas preferências perante um mercado tão concorrido (SCHIFFMAN; KANUK, 2009; SOLOMON, 2016)

Segundo Cobra e Urdan (2017), os consumidores são totalmente distintos uns dos outros, pois assumem as mais variadas formas. Tal constatação torna-se perceptível com base nas suas escolhas de compras, seja nos produtos como nas marcas. $\mathrm{O}$ ponto crucial reside no entendimento desses indivíduos e das suas diferenças e, consequentemente, nos seus agrupamentos no processo de marketing, de modo que se possa compreender a individualidade e propensão de cada um.

Para se compreender melhor o comportamento do consumidor, a figura 1 ilustra questões abordadas durante o processo de consumo: 


\section{FELIZ ANIVERSÁRIO(S): A INFLUÊNCIA NO COMPORTAMENTO DAS CONSUMIDORAS MÃES NA REALIZAÇÃO DOS MESVERSÁRIOS}

Figura 1 - Estágios do processo de consumo

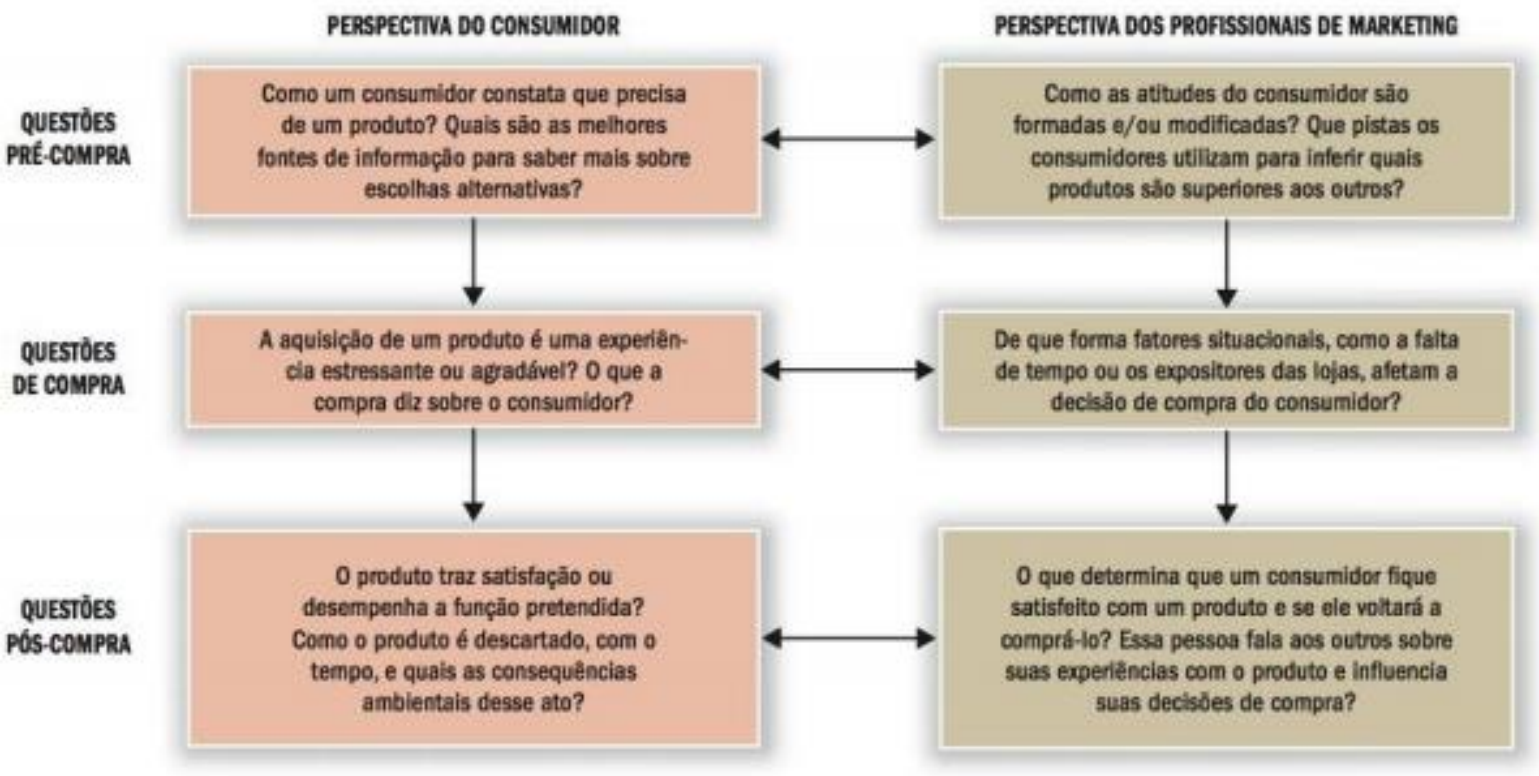

Fonte: Solomon (2016)

A figura 1 relata três processos, (as questões pré-compra) nessa primeira fase, o consumidor busca de toda forma satisfazer sua necessidade, por exemplo, mostrar a todos os contatos em plataformas digitais a evolução e a beleza do bebê em diversas caracterizações, mês a mês. Assim, essas consumidoras irão adquirir informações, sobre marca, modelo, preço, praça, promoção com pesquisa via internet, mídias diversas, entre outros. E, por fim escolhe a melhor forma financeira para adquirir seu produto (SOLOMON, 2016).

Ainda de acordo com o autor referenciado no parágrafo anterior, no segundo processo (as questões de compra), o cliente compra a ideia, ou seja, se o vendedor souber vender, com certeza fará uma venda, sempre sendo honesto com o cliente, falando a verdade e obtendo a confiança do cliente, e falando os respectivos pontos fortes e fracos do produto.

E, por fim, no terceiro processo (as questões pós compra), a venda não acabou, é nessa fase que se obtém a satisfação do cliente, é essa satisfação que determinará o sucesso do produto, apenas no uso/consumo que o cliente terá a certeza da qualidade do produto.

O estudo do comportamento do consumidor entende aquilo que está ligado aos recursos que os consumidores aplicam em itens para consumo, o que se relaciona com o marketing e como o mesmo busca identificar as necessidades para induzir o cliente a consumir o produto (VIEIRA 2002). De acordo com Mendes (2014), pode-se observar as oportunidades e ameaças de um determinado projeto, observando daí quais as melhores estratégias para o lançamento de um produto/serviço ou a sua divulgação, estabelecendo uma melhor comunicação entre a empresa e o consumidor ou direcionando-o ou influenciando-o para determinadas escolhas.

\subsubsection{Influencias no comportamento do consumidor}




\section{FELIZ ANIVERSÁRIO(S): A INFLUÊNCIA NO COMPORTAMENTO DAS CONSUMIDORAS MÃES NA REALIZAÇÃO DOS MESVERSÁRIOS}

O comportamento do consumidor é complexo e, muitas vezes, difícil de se compreender. No que tange a influência, o consumidor pode ser induzido por dois tipos de influência na aquisição de um produto/serviço: a interna ou a externa. Mendes (2014) aponta que na influência interna, o consumidor é envolvido pelas suas necessidades, ou seja, ele adquire o produto/serviço que irá satisfazê-lo conforme ao que necessita. Relativamente às influências externas, o autor aponta que as mesmas estão classificadas por fatores, sendo eles: culturais, sociais e psicológicos.

Dessa forma, segundo Silva (2019), o consumidor é movido por diversas influências, é como um iceberg flutuante, embaixo da água temos exatamente os motivos pelos quais ele adere aquele produto/serviço (Influências Internas), submerso temos as ações que influenciam na decisão de compra (Influências Externas), assim é necessário verificar as influências que moldam o comportamento do consumidor antes de sua tomada de decisão.

As influências internas são representadas pelos fatores psicológicos, que, por sua vez, podem ser separados em quatro fases: Motivação, Percepção, Aprendizagem, Crenças e atitudes (BINOTTO, 2014), conforme descritos no Quadro 2.

Quadro 2 - Fatores Psicológicos

\begin{tabular}{|c|l|}
\hline Fatores & \multicolumn{1}{c|}{ Contextualização } \\
\hline Motivação & $\begin{array}{l}\text { Ela é demonstrada a partir do momento em que o consumidor deseja comprar algo, ela } \\
\text { o impulsiona a adquirir aquele produto/serviço. }\end{array}$ \\
\hline Percepção. & $\begin{array}{l}\text { As pessoas costumam criar uma realidade diferente do que realmente é, isto é, o } \\
\text { consumidor julga com base nas suas percepções, podendo ser influenciado pela marca, } \\
\text { tamanho, cor, entre outros. }\end{array}$ \\
\hline Aprendizagem & O indivíduo adquire o conhecimento e a experiência, ou seja, é o ato de aprender. \\
\hline Atitudes & $\begin{array}{l}\text { As crenças dos consumidores são consideradas uma estratégia de marketing, em que o } \\
\text { consumidor irá acreditar, no desenvolvimento do produto, do preço, da promoção, da } \\
\text { praça, entre outros. Em outras palavras, crença é acreditar em algo, atitude é ir atrás } \\
\text { daquilo que você acredita, a atitude é a ação do consumidor. }\end{array}$ \\
\hline
\end{tabular}

Fonte: Adaptado de Binotto (2014)

Os consumidores mudam suas necessidades, seus desejos, suas motivações, percepções continuamente. Dessa forma, as organizações precisam entender os seus consumidores atuais e aqueles considerados potenciais. Os fatores descritos no quadro 2 mostram que tais elementos estão ligados a mente do indivíduo, se fazendo de suma importância conhecer os consumidores em seus diferentes costumes, culturas e personalidades (BINOTTO 2014).

Relativamente às influências externas, os fatores culturais são desenvolvidos desde a infância, em que a criança recebe profundas influências da sociedade e cujos valores e crenças da sociedade são passados de geração para geração (TEIXEIRA, 2010). No ambiente familiar, isto é reforçado pelas escolas, instituições e igrejas. As ações, músicas ouvidas, a alimentação, entre outras questões, sofre impacto, em grande parte, pela cultura em que o indivíduo está inserido. Para Giareta (2011), a cultura, de certa forma, é o direcionamento dos desejos e do comportamento do ser humano, servindo para orientar o comportamento do consumidor com base nas crenças, valores e costumes aprendidos. 


\section{FELIZ ANIVERSÁRIO(S): A INFLUÊNCIA NO COMPORTAMENTO DAS CONSUMIDORAS MÃES NA REALIZAÇÃO DOS MESVERSÁRIOS}

As situações externas em que o indivíduo está inserido afeta no seu comportamento, seja no local da compra, na localização geográfica, no clima, na decoração da loja, entre diversas situações em que o cliente pode observar. O ambiente pode influenciar também conforme comentários e percepções feitas por outras pessoas. Em outras palavras, de forma cultural, quando um produto/serviço não está sendo mais aceito é sinal que os valores e costumes sofreram modificações, o que pode impactar no poder de decisão dos consumidores. Assim, as organizações precisam estar atentas a essas mudanças (BINOTTO 2014).

E, por fim, nas influências externas, surgem os fatores sociais. Secco, Oliveira e Amorim, (2014) relatam que tais fatores estão interligados a família, status, amigos, e outros meios da sociedade. Estes fatores afetam intensamente o comportamento do consumidor no momento da compra, pelo fato do contato com pessoas de sua afinidade. Segundo Giareta (2011) os fatores sociais englobam grupos de referência distintos, tais como: família, amigos, classes sociais, entre outros, que acabam por impactar o comportamento do consumidor.

Na visão de Binotto (2014), as famílias influenciam a partir do momento em que impõem limites nas compras dos filhos. Com frequência, elas afetam as suas decisões de compra, pois geralmente uns compram para os outros, e/ou para a família toda. Logo, a família está entre a influenciadora mais importante para a maioria dos consumidores. Já a classe social consiste na posição do indivíduo, segundo a sua riqueza e poder. Assim, no que se refere aos grupos de referência, compartilham valores de sua cultura, subcultura e hierarquia social.

Em suma, as pessoas são as responsáveis por influenciar os pensamentos, sentimentos e comportamentos dos consumidores (BINOTTO 2014). De acordo com Teixeira (2010), ao se estudar o comportamento do consumidor, não se pode desconsiderar a interação social e a posição em que o indivíduo está inserido na sociedade. Desse modo, deve-se entender que a ação entre dois indivíduos é uma troca, em que as ações de um, provoca resultados nas ações do outro, e essa interação é um ponto crucial no que se diz respeito às influências no comportamento do consumidor, podendo ter impacto nas mais diversas situações e segmentos como o consumo de produtos/serviços nos mais variados segmentos como o alimentício, de moda, infantil, entretenimento e assim por diante.

\section{$1.2 \mathrm{O}$ fenômeno do mesversário}

Dentro das indústrias que mais faturam no mundo, está a indústria de entretenimento, Para Carvalho, Silva e Barros (2012), ao longo do tempo, o entretenimento cresceu e continua em um processo de desenvolvimento, produzindo ideias, conteúdo, informações, ciência, arte e diversão, em que a difusão cultural, de modo geral, alcança cada vez mais uma parcela maior da sociedade. O entretenimento é uma espécie de diversão, como tantos outros, podendo ser adquirido como serviço, prestado por empresas ou pessoa física, sendo caracterizadas como um tipo de consumo. Em suma, pode-se afirmar que entretenimento e consumo são duas práticas que caminham juntas (ROCHA; BARROS; KARAM, 2014).

No que concerne ao entretenimento, os eventos funcionam como o acontecimento em que se registaram as reuniões de indivíduos em determinada data ou local (LIMA, 2019). Vale ressaltar que, muitas vezes, ele não pode ou não tem como ser refeito, por isso a exigência de um planejamento cauteloso de modo a garantir o seu sucesso. Dentro desse contexto, o mercado de festas segue em crescimento acelerado. Estima-se que no Brasil existem mais de 12 mil estabelecimentos registrados, voltados 


\section{FELIZ ANIVERSÁRIO(S): A INFLUÊNCIA NO COMPORTAMENTO DAS CONSUMIDORAS MÃES NA REALIZAÇÃO DOS MESVERSÁRIOS}

para este tipo de evento, cujo segmento infantil é o que mais cresce e se destaca (CASANELI, 2009). As festas infantis são serviços customizados e flexíveis, pois visam atender as necessidades dos clientes, o que, diversas vezes, resultam em maiores custos de produção e de entrega padronizada. Desse modo, as empresas organizadoras de festas infantis buscam inovar ao tratar de itens como embalagens, brincadeiras, imagens e outros recursos, oferecendo diversidade para os pais (OLIVEIRA, 2015).

Segundo o Portal De Eventos (2019), o mercado de festas e eventos cresce 14\% ao ano, cujo mercado de festas infantis, especificamente, vem se evidenciado entre os demais. Os pais não têm poupado quando se trata da comemoração dos aniversários dos seus filhos. Tal comportamento reflete-se nos valores. Estimou-se que no ano de 2017 o setor tenha movimentado cerca de $\mathrm{R} \$ 17$ bilhões em festas infantis. Tais eventos despertam a interação entre pessoas, sejam elas conhecidas ou desconhecidas. Dentre os mais variados tipos de festas infantis destacam-se: festas de aniversários, geralmente feitas para crianças de 1 a 12 anos e festas realizadas antes do nascimento dos filhos (chás de bebês e revelação). No entanto, entre essas duas comemorações há a realização dos mesversários, representado pela comemorado do mês-a-mês do nascimento da criança (LIMA 2019).

Segata (2017) relata que, na fase da gestação, as mamães realizam os chás de bebês como um tipo de confraternização que incluem familiares, amigos e colegas de trabalho. Contudo, com a chegada dos bebês, os relacionamentos desses grupos vão se solidificando e surge uma nova sociabilidade como forma de atualização de vínculos e reafirmação da comunidade, os mesversários. Essa prática acontece ao longo dos doze meses iniciais de vida das crianças, em que, após esse período, as comemorações passam a ser os aniversários anuais. O Portal G1 (2017) relata que empresários do segmento de festas apontam um crescimento de $30 \%$ no faturamento de suas lojas desde que esse tipo de comemoração passou a existir.

A ideia do mesversário é compor uma memória do momento, não envolve, a princípio, custos muito altos com grandes celebrações que envolvem preparativos caros e uma quebra de rotina, sendo realizado em casa de forma simples e prática (SEGATA, 2017). O propósito reside no compartilhamento com os grupos de referência, de uma forma geral, da evolução, e crescimento do bebê, denotando o orgulho e a felicidade dos pais e, principalmente da mãe, normalmente idealizadora e executora do projeto.

Em suma, verifica-se que os mesversários, inicialmente, não necessariamente possui um custo financeiro alto, a não ser que seja da vontade da família e que o poder aquisitivo e financeiro permita gastos maiores. No entanto, o conceito principal centrase em algo mais intimista, envolvendo uma centralização na doçura das crianças, diante do seu desenvolvimento mês-a-mês. Imagens partilhadas em mídias sociais geram notícias dando ainda mais relevância a este tipo de evento. Dessa forma, verifica-se que tal movimento desencadeou em registros pensados e montados levando em consideração justamente a sua publicação, gerando uma satisfação e uma alegria para os pais em poder partilhar esses momentos e, consequentemente, curtir a sua notoriedade (SEGATA, 2017).

\section{PROCEDIMENTOS METODOLÓGICOS}

O presente estudo possui o objetivo de analisar qual(is) fator(es) influenciam as consumidoras mães na realização dos mesversários. Com base nisso, optou-se por utilizar a abordagem qualitativa que, segundo Medeiros, Varela e Nunes (2017), tem como foco entender, defender e explicar os fenômenos sociais de maneiras diferentes, conhecendo as experiências, interações e documentos em seu contexto. 


\section{FELIZ ANIVERSÁRIO(S): A INFLUÊNCIA NO COMPORTAMENTO DAS CONSUMIDORAS MÃES NA REALIZAÇÃO DOS MESVERSÁRIOS}

Para a coleta de dados, foi utilizado um roteiro de entrevista estruturado com 9 perguntas, inspirados na revisão bibliográfica deste trabalho. De acordo com Arnoldi (2017), a entrevista estruturada é construída a partir de questões formalmente elaboradas, é padronizada, com uma linguagem clara e objetiva, onde obtém informações com respostas curtas e concisas. Para tal, foi utilizado o software Google Forms para elaboração e inserção das perguntas e o envio foi via WhatsApp. A decisão por estes meios residiu com base nos acontecimentos atuais, mais precisamente perante o avanço da COVID-19, exigindo um comportamento de reclusão e de isolamento social da população. Dessa forma, tais mecanismos foram utilizados para a coleta no período de 10 à 13/04/20, de modo a garantir maior segurança e agilidade para as respondentes.

Para a escolha dos sujeitos da pesquisa, foi empregada a técnica do snowball sampling que, conforme Baldin e Munhoz (2011), é realizada da seguinte maneira: os entrevistados iniciais indicam outros participantes e assim, sucessivamente, até que seja alcançado o objetivo proposto. Logo, para esta pesquisa, 21 mulheres concederam as entrevistas. Para manter a discrição e a privacidade das participantes, foram utilizados pseudônimos para a obtenção das declarações. Além disso, foi utilizado o recurso do Ipsis Litteris, de forma a garantir a veracidade na transcrição dos relatos dos participantes, mesmo constando qualquer desvio de ordem gramatical. Segue abaixo um quadro com o perfil das participantes.

Quadro 3 - Perfil das Participantes

\begin{tabular}{|c|c|c|c|c|c|}
\hline Entrevistadas & Idade & Escolaridade & Cargo em que trabalha & $\begin{array}{l}\mathrm{N}^{\circ} \text { de } \\
\text { Filhos }\end{array}$ & $\begin{array}{c}\text { Mesversários } \\
\text { realizados }\end{array}$ \\
\hline Entrevistada 1 & 24 & Ensino Médio & Operador de Produção & 1 & 11 \\
\hline Entrevistada 2 & 28 & Ensino Médio & Operador de Caixa & 2 & 10 \\
\hline Entrevistada 3 & 40 & Pós-Graduação & Professora & 2 & 17 \\
\hline Entrevistada 4 & 26 & Ensino Superior & Téc. em Segurança do Trabalho & 1 & 11 \\
\hline Entrevistada 5 & 23 & Ensino Médio & Dona de Casa & 1 & 4 \\
\hline Entrevistada 6 & 32 & Pós Graduação & Autônoma & 1 & 11 \\
\hline Entrevistada 7 & 26 & Ensino Superior & Dona de Casa & 1 & 1 \\
\hline Entrevistada 8 & 27 & Ensino Superior & Doula & 1 & 11 \\
\hline Entrevistada 9 & 32 & Graduação & Empresária & 2 & 6 \\
\hline Entrevistada 10 & 39 & Graduação & Professora & 2 & 2 \\
\hline Entrevistada 11 & 34 & Graduação & Advogada & 1 & 11 \\
\hline Entrevistada 12 & 26 & Pós Graduação & Professora & 1 & 11 \\
\hline Entrevistada 13 & 33 & Pós Graduação & Professora & 1 & 11 \\
\hline Entrevistada 14 & 34 & Pós Graduação & Médica & 1 & 11 \\
\hline Entrevistada 15 & 27 & Pós Graduação & Pedagoga & 1 & 11 \\
\hline
\end{tabular}


FELIZ ANIVERSÁRIO(S): A INFLUÊNCIA NO COMPORTAMENTO DAS CONSUMIDORAS MÃES NA REALIZAÇÃO DOS MESVERSÁRIOS

\begin{tabular}{|l|c|c|c|c|c|}
\hline Entrevistada 16 & 32 & Graduação & Operadora de Montagem & 2 & 8 \\
\hline Entrevistada 17 & 36 & Pós-Graduação & Servidora Pública & 2 & 22 \\
\hline Entrevistada 18 & 29 & Ensino Superior & Auxiliar de Coordenação & 1 & 11 \\
\hline Entrevistada 19 & 34 & Pós Graduação & Analista & 1 & 6 \\
\hline Entrevistada 20 & 26 & Graduação & Policial Militar & 1 & 11 \\
\hline Entrevistada 21 & 29 & Pós-Graduação & Nutricionista & 1 & 10 \\
\hline
\end{tabular}

Fonte: Elaboração própria (2020)

E, por fim, para analisar os dados, o método escolhido foi o da análise de conteúdo. Flick (2009) aponta que este meio é utilizado para realizar a interpretação após a coleta de dados, trazendo uma interpretação mais precisa e uma técnica refinada diante das declarações dos entrevistados, classificando os principais termos em categorias. Logo, com base no que afirma o referido autor, as etapas utilizadas foram: pré-análise, exploração do material e tratamentos dos resultados, inferência e interpretação. Partindo deste princípio, o estudo está dividido, a priori, em três categorias: Processo decisório; Comportamento de consumo das mães; Influências internas e externas. As mesmas foram baseadas na revisão bibliográfica e nos objetivos específicos propostos. A seguir, as categorias serão analisadas na próxima seção.

\section{ANÁLISE DOS RESULTADOS}

A análise dos resultados segue a sequência de perguntas anexadas ao questionário. Partindo desse pressuposto, foram identificadas as categorias: i) processos decisórios; ii) o comportamento do consumidor; e iii) as influências existentes em todo o processo que envolve o consumo do indivíduo. Foram coletados os depoimentos dados pelas respondentes, expostos nas categorias, sendo apresentadas as declarações que mais se destacaram nas perguntas realizadas, descritas no decorrer das análises.

\subsection{Processo Decisório}

De acordo com o questionamento 1, "Como você chegou à conclusão de que precisava fazer o(s) mesversário(s)?” foram apresentadas as seguintes respostas:

Entrevistada 3: "Pra ter uma lembrança dos meses que passam e quando vemos já foi um ano. Agradecer a Deus por cada mês e conquista do bebề".

Entrevistada 6: "Depois que conheci a história de como surgiu os mesversários e também porque me sentia feliz em juntar pessoas para comemorar mais um mês vencido de novos desafios"

Entrevistada 16: "Antes de engravidar achava besteira fazer mesversário, tinha como algo supérfluo. Até mesmo durante a gravidez não pensava em fazer. Mas após o nascimento veio o desejo de celebrar o primeiro mês de vida e aí vira um ciclo fazemos um e ficamos pensando no tema seguinte." 


\section{FELIZ ANIVERSÁRIO(S): A INFLUÊNCIA NO COMPORTAMENTO DAS CONSUMIDORAS MÃES NA REALIZAÇÃO DOS MESVERSÁRIOS}

Entrevistada 20: "Comemorar cada conquista, cada fase, cada dificuldade e agradecer por passar e por ter minha filha cheia de saúde a cada mês."

Diante das respostas apresentadas pelas entrevistadas, nota-se que celebrar a vida da criança foi um fator decisivo para a realização dos mesversários. Observa-se que as mães tratam os mesversários como uma celebração, realizados de forma a comemorar o nascimento, a vida, a saúde, e os desafios que aparecem a cada ciclo. Segundo Segata (2017), esse evento evidencia a felicidade dos pais em realizar esse momento, visto que é uma forma de observar também a evolução da criança.

Ao passar para o questionamento 2, "Na sua opinião, como foi a experiência da realização do(s) mesversário(s), agradável ou estressante? Justifique a sua resposta." os relatos demonstraram:

\footnotetext{
Entrevistada 3: "As duas, enquanto estamos na licença maternidade é uma festa, mais quando junta trabalho, Mesversário e rotina diária vira estresse."

Entrevistada 14: "Agradável. Fiz algo elaborado nos dois primeiros meses, esses foram estressantes e dispendiosos, mas depois comecei a fazer apenas um bolo para as pessoas de casa mesmo e ficou algo leve e agradável."

Entrevistada 15: "No início foi agradável, a partir do $4^{\circ}$ mesversário começou a ficar estressante por causa da influência e insistência dos familiares."

Entrevistada 21: "Estressante na hora de fazer as coisas, pois eu quem fazia tudo (exceto bolo), mas na hora da mesa pronta e das fotos eu ficava satisfeita eu estar celebrando mais um mês de vida do meu filho conosco."
}

Como pode ser observado acima, há um misto de agradabilidade e estresse, porém verifica-se que, segundo as mães, ao unir a rotina e a influência dos familiares surge o estresse. A satisfação e a agradabilidade do evento tornam-se despercebida no decorrer do processo, diante de toda a organização, só realmente virando uma satisfação quando todos os preparativos são finalizados. Para Secco, Oliveira e Amorim (2014), tais decisões estão interligadas a família. Logo, percebe-se que estes fatores afetam consideravelmente o comportamento das consumidoras mães no momento da compra, baseado no contato com essas pessoas do ambiente familiar.

Nesse sentido, segundo Giareta (2011), a família está entre a influenciadora mais importante para a maioria das consumidoras. Em outras palavras, a família é a classe mais representativa no que concerne à tomada de decisão.

Partindo para o questionamento 3, "Você indicaria essa experiência para outras mães? Por que?", foram apresentadas as seguintes declarações:

Entrevistada 7: "Sim, para aquelas mães que têm apoio para ajudar na organização. Mas também existem os kits mesversário que facilita muito. É uma forma de encontrar pessoas queridas e criar um vínculo com elas e seu bebê."

Entrevistada 14: "Sim. Gosto de guardar as fotos dos mesversários e relembrar cada marco do desenvolvimento dela. Além de ver sua evolução física."

Entrevistada 16: "Sim. Por que pra mim representa como uma comemoração por mais um mês, é um motivo para celebrar juntamente com as pessoas que amamos." 


\section{FELIZ ANIVERSÁRIO(S): A INFLUÊNCIA NO COMPORTAMENTO DAS CONSUMIDORAS MÃES NA REALIZAÇÃO DOS MESVERSÁRIOS}

Entrevistada 21: "Sim. Pois apesar de estressante, é uma forma de celebrar a vida (no meu ponto de vista)."

Diante do exposto, é possível notar que, apesar de todo o estresse identificado nos preparativos para a realização, nota-se o quão gratificante é para as mães comemorar cada mês de vida dos seus bebês com as pessoas que elas amam. Além disso, há a possibilidade das pessoas, de um modo geral, criarem um vínculo com o bebê e dos momentos vivenciados nos mesversários gerarem um acompanhamento da evolução física da criança por meio das fotos registradas nestes eventos. Este propósito vai ao encontro do que afirma Segata (2017), de uma forma geral, da evolução, e crescimento do bebê, denotando o orgulho e a felicidade das mães, normalmente idealizadora e executora do projeto.

\subsection{Comportamento de consumo das mães}

De acordo com o questionamento 4, "Depois de decidir pela realização do evento, descreva todo o processo que foi feito, etapa a etapa, até a chegada do grande dia." foram apresentadas as seguintes respostas:

\footnotetext{
Entrevistada 5: "Quando termino um mesversário vou procurar os modelos de bolos vou procurar docinhos diferente pra fazer, vou procurar as ideias simples de decoração quando falta uma semana eu começo a colocar em prática."

Entrevistada 14: "Eu encomendava o bolo uns dias antes. Não tinham tantos processos porque decidi que seriam eventos simples."

Entrevistada 16: "É tantos pensamentos, escolhe tema, muda tema, depois que de fato decide o tema, procura o modelo do bolo, começa a pensar na decoração, ver o q dar pra fazer se naquele mês dá pra exagerar e gastar um pouco mais., depois escolhe os fornecedores, ver o que foi melhor e aproveita para experimentar produtos de outras pessoas que você não conhecia o trabalho. Após tudo planejado é só aguardar o dia e realizar o planejado, se surgir imprevistos será normal e adequamos diante da situação. Enquanto executo a ansiedade toma conta como se fosse a festa de 1 aninho, emoção essa que se repete todos os meses."

Entrevistada 17: "Escolhia o tema, decidia o cardápio, as comidas e os itens da decoração. A prioridade era a simplicidade e optava sempre por fazer temas em que eu pudesse utilizar os materiais que eu tinha em casa, na maioria das vezes."
}

Com base nos questionamentos acima, pode-se observar que as mães normalmente optam por algo simples e que envolvam poucos convidados, muitas vezes utilizando materiais que já tenham na sua própria casa, havendo toda uma preparação para o dia da comemoração. A comemoração dos mesversários, é realizada mantendo uma conotação simples, corroborando com as observações feitas por Segata (2017), centra-se em algo mais particular, envolvendo uma atenção na doçura das crianças, diante do seu desenvolvimento mês-a-mês.

Ao passar para o questionamento 5, "Na sua opinião, há diferença na sensação da realização do primeiro mesversário para os outros que são feitos a seguir? Explique esses sentimentos.", os relatos demonstraram que: 
Entrevistada 15: "Sim! O primeiro foi mágico, encantador, pois estava radiante com o primeiro mês de vida da minha pequena e isso me motivou. Os seguintes eu percebi que haviam outras comemorações a serem feitas sem precisar do estresse de uma festa."

Entrevistada 16: "Há diferença sim. O primeiro é meio que um teste e você ver que é tão bom realizar que se empolga e quer fazer outros, pois para cada um é diferente do outro e cada um se torna único."

Entrevistada 17: "Sim. O primeiro vem cheio de expectativas, quando o bebê completa um mês daquela espera tão ansiosa em que ele estava na barriga. Com o passar dos meses, talvez pelo cansaço da rotina, principalmente os mesversários que fiz depois da volta ao trabalho, ficaram mais cansativos. No período da licença maternidade as comemorações foram um pouco mais elaboradas e mais trabalhadas."

Entrevistada 18: "Sim, O primeiro é de fato a comemoração do primeiro mês de vida da sua maior bênção, o seu primeiro mês como mãe, $O$ primeiro mês da família, o puerpério para quem passa não é fácil, então é uma comemoração de tudo."

Como pode ser observado, as mães sentem que o primeiro mês é o mais importante, talvez pelo misto de sentimentos adotados durante a gestação e que, naquele momento, torna-se uma realidade em suas vidas, relatam também que com o passar dos meses fica cansativo a comemoração mês a mês, levando a considerar que, dentre os fatores psicológicos existentes, o da motivação é o que mais se destaca e estimula essas mães, mensalmente, na realização dos mesversários. Para Binotto (2014), a motivação é demonstrada a partir do momento em que o consumidor deseja algo. Em outras palavras, tal sensação é resultante do nascimento da criança, gerada pela expectativa das mães.

Partindo para o questionamento 6, "Descreva como o uso dos recursos financeiros foi pensado para a realização do (s) mesversário(s) e o que isso representou para a dinâmica de gastos da família. ”, foram apresentadas as seguintes declarações:

Entrevistada 1: "Sempre procuramos não gastar muito nós mesversários, programando uma quantia $\mathbf{X}$ para cada mês e contávamos também com a colaboração dos avós..."

Entrevistada 5: "Eu pensei em fazer tudo simples sem muito gasto uma coisa só pra família sem muita decoração cara"

Entrevistada 14: "Eu determinei que não gastaria mais que 100 reais. Assim não houve comprometimento."

Entrevistada 16: "Na verdade no primeiro mês ficamos apreensivos, pois geralmente, devido ao pós parto e ao nascimento do bebé consequentemente os gastos aumentam um pouco, mas o desejo de fazer é tão grande que até deixamos um pouco de lado pensar nos gastos. Eu particularmente não planejei nada financeiramente falando, mas após o primeiro acabei que encaixei no orçamento mensal um valor pra gastarmos. Procuro não exagerar nos gastos, faço algo simples, não tão caro, mas com significado enorme." 


\section{FELIZ ANIVERSÁRIO(S): A INFLUÊNCIA NO COMPORTAMENTO DAS CONSUMIDORAS MÃES NA REALIZAÇÃO DOS MESVERSÁRIOS}

Diante do exposto, percebe-se que o mesversário é uma comemoração em que as mães não gastam muito do seu orçamento, é possível observar que algumas estabelecem um valor mensal, outras contam com a colaboração dos familiares mais próximos, nesse caso, os avós. Estima-se os mesversários como um evento simples, mais particular, sem muita decoração e para os mais íntimos da família. Segundo Segata (2017), verifica-se que os mesversários, inicialmente, não precisam possuir um custo financeiro alto, a não ser que seja da vontade da família e que o poder aquisitivo e financeiro permita gastos maiores, e obtenha ajuda dos familiares mais próximos.

\subsection{Influências internas e externas}

De acordo com o questionamento 7, "Como a opinião das pessoas que convive com você foi importante para a realização do(s) mesversário(s)?” foram apresentadas as seguintes respostas:

Entrevistada 1: "Essa questão varia de pessoa pra pessoa, alguns davam força enquanto outros não eram muito a favor, porém sempre pensei em fazer todos os mesversários independente de opiniões."

Entrevistada 13: "Foi importante, pois me incentivaram." Entrevistada 15: "Foi péssimo! Pois queriam intervir em tudo."

Entrevistada 21: "A maioria me estimulava a fazer, então foi mais fácil."

A influência da família é importante em um momento como este, nota-se que as mães sofrem essa influência externa de uma maneira forte e constante. Observa-se que na proporção em que esse grupo de referência estimula a realização do mesversário, outros intervieram de forma negativa. Contudo, o seu poder de influência é, em sua maioria, positivo para o momento da celebração. As pessoas são, a priori, as responsáveis por influenciar os pensamentos, sentimentos e comportamentos dos consumidores (BINOTTO 2014). Logo, a família está entre a influenciadora mais importante para a maioria dos consumidores.

Ao passar para o questionamento 8, "Descreva como é a cultura de festas ou eventos infantis em sua família." os relatos demonstraram:

Entrevistada 2: Bom, gostamos tanto de comemorar aniversário que até pros cachorros fazemos festa, kkkkkkk."

Entrevistada 10: "Costumamos comemorar com bolo. balões personalizados a cada mês. Mas, nada de mega evento tudo feito em casa mesmo."

Entrevistada 12: "Comemoramos sem festões. Apenas se fazem presente nas festas, quem se faz presente sempre. Seja família ou não."

Entrevistada 17: "Sempre comemoramos em casa, com os mais próximos e sempre faço, junto com minha família, a maioria das coisas."

Entrevistada 20: "Sempre comemoramos aniversários, desde a alguns com festas grandes como outros com um simples bolinho pra não passar em branco, mas comemoramos e gostamos de comemorar!!" 


\section{FELIZ ANIVERSÁRIO(S): A INFLUÊNCIA NO COMPORTAMENTO DAS CONSUMIDORAS MÃES NA REALIZAÇÃO DOS MESVERSÁRIOS}

Como pode ser observado, de acordo com a cultura familiar apresentada pela maioria das respondentes, comemorar independe da situação, seja uma festa maior ou algo mais simples, a grande maioria opta por algo discreto e com poucos convidados, apenas para não passar em branco. Estes eventos tornam-se significativo para as famílias, e não é por acaso que vem crescendo no decorrer dos anos. Segundo o Portal de Eventos (2019), o mercado de festas e eventos cresce $14 \%$ ao ano, e o de festas infantis, especificamente, vem se evidenciado entre os demais. Os pais não têm poupado quando se trata da comemoração dos aniversários dos seus filhos. Tais eventos despertam a interação entre pessoas, sejam elas conhecidas ou desconhecidas. Dentre os mais variados tipos de festas infantis destacam-se: festas de aniversários, geralmente feitas para crianças de 1 a 12 anos e festas realizadas antes do nascimento dos filhos (Chás de bebês e revelação).

Partindo para o questionamento 9, "Para concluir, descreva o que a levou a realizar o(s) mesversário(s) para o(s) seu(s) filho(s).", foram apresentadas as seguintes declarações:

\footnotetext{
Entrevistada 5: "Achei bem interessante e muitas pessoas estão fazendo, é bem divertido poder fantasiar ele fazer bolos com temas de desenho que ele gosta."

Entrevistada 7: "Fui muito influenciada por outras mães, kkkkkk"

Entrevistada 15: "Influência dos familiares."

Entrevistada 19: "O desejo da família."
}

Diante do exposto, sobre a influência do grupo de referência, destaca-se a família. Esta influência externa está diretamente associada a tomada de decisão das mães para a realização dos mesversários, em que o desejo da família barganha e influencia o desejo que deveria, a priori, partir da mãe. Verifica-se também que a mãe é induzida por amigas que também são mães e que já realizaram esse tipo de evento, ou seja, evidenciando a força das influências externas e dos fatores sociais. Segundo Giareta (2011), os fatores sociais englobam grupos de referência distintos, tais como: família, amigos, classes sociais, entre outros, que acabam por impactar o comportamento do consumidor.

Para concluir, a seguir será apresentado um quadro-resumo com os principais resultados encontrados nas categorias analisadas.

\subsection{Quadro-resumo com os principais achados nas categorias avaliadas}

Quadro 4- Resultados encontrados nas categorias analisadas

\begin{tabular}{|c|l|l|l|}
\hline CATEGORIAS & SUBCATEGORIAS & \multicolumn{1}{|c|}{ CÓDIGOS } & PRINCIPAIS RESULTADOS \\
\hline & $\begin{array}{l}\text { A necessidade de fazer } \\
\text { os mesversários. }\end{array}$ & $\begin{array}{l}\text { Lembrança; meses; } \\
\text { agradecer; conquista do } \\
\text { bebê; feliz; comemorar; } \\
\text { desafios; engravidar; } \\
\text { celebrar; vida; tema; } \\
\text { fase. }\end{array}$ & $\begin{array}{l}\text { Os mesversários são tratados como } \\
\text { uma celebração, realizados de } \\
\text { forma a comemorar o nascimento, a } \\
\text { vida, a saúde, os desafios que } \\
\text { aparecem a cada ciclo. }\end{array}$ \\
$\begin{array}{c}\text { Processo } \\
\text { Decisório }\end{array}$ & $\begin{array}{l}\text { A experiência na nação } \\
\text { realizán } \\
\text { mesversários. }\end{array}$ & $\begin{array}{l}\text { Mesversários; rotina; } \\
\text { estressantes; } \\
\text { dispendiosos; }\end{array}$ & $\begin{array}{l}\text { Ao unir a rotina e a influência dos } \\
\text { familiares surge o estresse. Só } \\
\text { realmente virando uma satisfação }\end{array}$ \\
\hline
\end{tabular}




\section{FELIZ ANIVERSÁRIO(S): A INFLUÊNCIA NO COMPORTAMENTO DAS CONSUMIDORAS MÃES NA REALIZAÇÃO DOS MESVERSÁRIOS}

\begin{tabular}{|c|c|c|c|}
\hline & & $\begin{array}{l}\text { agradável; influência; } \\
\text { insistência; satisfeita. }\end{array}$ & $\begin{array}{l}\text { quando todos os preparativos são } \\
\text { finalizados. }\end{array}$ \\
\hline & $\begin{array}{l}\text { Indicação } \quad \text { da } \\
\text { experiência para outras } \\
\text { mães. }\end{array}$ & $\begin{array}{lr}\text { Apoio; } & \text { pessoas } \\
\text { queridas; } & \text { vínculo; } \\
\text { relembrar; } \quad \text { evolução } \\
\text { física; celebrar; } & \text { apesar } \\
\text { de estressante. } & \end{array}$ & $\begin{array}{l}\text { As pessoas criam um vínculo com } \\
\text { os bebês, e dessa forma podendo } \\
\text { observar a evolução física do bebê, } \\
\text { através dos registros desses } \\
\text { momentos. }\end{array}$ \\
\hline \multirow{3}{*}{$\begin{array}{l}\text { Comportamento } \\
\text { de consumo das } \\
\text { mães }\end{array}$} & $\begin{array}{l}\text { Decisão pela realização } \\
\text { do evento, descrevendo } \\
\text { etapa por etapa, até a } \\
\text { chegada do grande dia. }\end{array}$ & $\begin{array}{lr}\text { Ideias; } & \text { simples } \\
\text { decoração; } & \text { eventos } \\
\text { simples; } & \text { ansiedade; } \\
\text { emoção; } & \text { prioridade; } \\
\text { materiais em casa. }\end{array}$ & $\begin{array}{l}\text { Os mesversários são feitos de forma } \\
\text { simples, sem muitos convidados, } \\
\text { com materiais que as mães já tem } \\
\text { em casa. }\end{array}$ \\
\hline & $\begin{array}{l}\text { Diferença na sensação } \\
\text { da realização do } \\
\text { primeiro mesversário } \\
\text { para os outros que são } \\
\text { feitos a seguir. }\end{array}$ & $\begin{array}{l}\text { O primeiro; mágico; } \\
\text { motivou; diferente do } \\
\text { outro; } \\
\text { expectativas; rotinico; } \\
\text { cansativos; puerpério; } \\
\text { comemoração de tudo. }\end{array}$ & $\begin{array}{l}\text { O primeiro mês é o mais } \\
\text { importante, porém nos outros meses } \\
\text { vai perdendo o encanto, tornando-se } \\
\text { um pouco cansativo devido a rotina. }\end{array}$ \\
\hline & $\begin{array}{lrr}\text { Uso dos } & \text { recursos } \\
\text { financeiros } & \text { para } & \text { a } \\
\text { realização } & \text { do(s) } \\
\text { mesversário(s) e o que } \\
\text { representou para os } \\
\text { gastos da família. }\end{array}$ & $\begin{array}{l}\text { Quantia X; sem muito } \\
\text { gasto; sem decoração } \\
\text { cara; não houve } \\
\text { comprometimento; não } \\
\text { exagerar; significado } \\
\text { enorme. }\end{array}$ & $\begin{array}{l}\text { Em sua maioria, as mães afirmaram } \\
\text { não gastar muito do seu orçamento } \\
\text { por ser algo simples, outras contam } \\
\text { com a colaboração dos familiares } \\
\text { mais próximos. }\end{array}$ \\
\hline \multirow{3}{*}{$\begin{array}{l}\text { Influências } \\
\text { internas e } \\
\text { externas }\end{array}$} & $\begin{array}{l}\text { A importância da } \\
\text { opinião das pessoas para } \\
\text { a realização do(s) } \\
\text { mesversário(s). }\end{array}$ & $\begin{array}{l}\text { Independente de } \\
\text { opiniões; importante; } \\
\text { incentivaram; intervir } \\
\text { em tudo; a maioria } \\
\text { estimulava. }\end{array}$ & $\begin{array}{l}\text { A família é uma influência forte e } \\
\text { constante, sempre estimula a } \\
\text { realização dos mesversários, em sua } \\
\text { maioria das vezes de forma } \\
\text { positiva. }\end{array}$ \\
\hline & $\begin{array}{l}\text { A cultura de festas ou } \\
\text { eventos infantis na } \\
\text { família. }\end{array}$ & $\begin{array}{lr}\text { Comemorar; } & \text { festas; } \\
\text { nada de mega evento; } \\
\text { sem festões; } & \text { sempre } \\
\text { comemoramos; } & \text { um } \\
\text { simples bolinho; não } & \\
\text { passar em branco. }\end{array}$ & $\begin{array}{l}\text { As famílias, em sua maioria, optam } \\
\text { por algo discreto e com poucos } \\
\text { convidados, apenas para não passar } \\
\text { em branco. }\end{array}$ \\
\hline & $\begin{array}{ll}\text { Motivos } & \text { de realização } \\
\text { do(s) } & \text { mesversário(s) } \\
\text { para o(s) } & \text { seu(s) filho(s). }\end{array}$ & $\begin{array}{l}\text { Interessante; família; } \\
\text { influenciada por outras } \\
\text { mães; influência dos } \\
\text { familiares; o desejo da }\end{array}$ & $\begin{array}{l}\text { A família e os amigos estão } \\
\text { diretamente associados a tomada de } \\
\text { decisão das mães para a realização } \\
\text { dos mesversários, em que o desejo } \\
\text { da família barganha e influencia o } \\
\text { desejo que deveria, a priori, partir } \\
\text { da mãe. }\end{array}$ \\
\hline
\end{tabular}

Fonte: Elaboração própria (2020).

É relevante destacar que, conforme exposto no quadro 4, a relevância do estudo busca não descrever o evento do mesversário, pois a sua dinâmica, por si só, já é 


\section{FELIZ ANIVERSÁRIO(S): A INFLUÊNCIA NO COMPORTAMENTO DAS CONSUMIDORAS MÃES NA REALIZAÇÃO DOS MESVERSÁRIOS}

bastante disseminada no contexto materno e no cotidiano das famílias com bebês. No entanto, o estudo busca evidenciar e compreender como esta celebração tem ganhado espaço e representatividade. Nesse sentido, percebe-se que a sua capacidade adaptativa é um dos seus grandes atrativos, encaixando-se nos variados padrões financeiros familiares. No decorrer os capítulo, foi discorrido e verificado em como os resultados encontrados corroboraram com a revisão de literatura explorada neste estudo, ratificando e consolidando, por meio de uma aderência empírica das entrevistas, a revisão teórica produzida até então.

\section{CONSIDERAÇÕES FINAIS}

Este trabalho teve como intuito analisar as influências no comportamento das consumidoras mães na realização do(s) mesversário(s). Assim, diante do que foi exposto, o presente estudo trouxe o seguinte problema de pesquisa: Qual(is) fator(es) influenciam as consumidoras mães na realização dos mesversários?

Com o propósito de responder este questionamento, foram elencados três objetivos específicos para viabilizar esta atividade. No que diz respeito ao primeiro objetivo específico, identificar as influências internas e externas no comportamento de compra das consumidoras mães, nota-se que a família é a principal influência externa, seja muitas vezes com pontos positivos, outros negativos. Nesse sentido, o desejo da família barganha, o que deveria de fato, ser um desejo inicial dos pais. Portanto, no que compete a influência interna, observa-se que o fator psicológico da motivação se destaca entre os demais, ou seja, o desejo de comemorar o nascimento do filho(a), em celebrar todo mês vai aumentando de acordo com as motivações que vão surgindo mensalmente nas comemorações.

No que tange ao segundo objetivo específico, verificar como acontece o processo decisório de adesão a prática do(s) mesversário(s), percebe-se que celebrar a vida das crianças é um fator decisivo na realização do(s) mesversário(s), pois as mães tratam estes eventos como uma celebração, realizados de forma a comemorar o nascimento, a vida, a saúde, e os desafios que aparecem a cada ciclo.

Em relação ao terceiro objetivo específico, examinar a relação entre as influências e a realização do(s) mesversário(s), verifica-se que, as mães sofrem influências externas e internas, sendo a família o grupo de referência que mais se evidencia entre os demais e o que mais impacta na decisão de realização dos mesversário(s). Entretanto, é notório que, apesar dessa influência, as mães realizam os mesversário(s) como forma de celebrar a vida da criança e também de estabelecer/fortalecer um vínculo com as pessoas que fazem parte da vida do bebê.

$\mathrm{E}$, por fim, no que se refere ao objetivo geral, analisar qual(is) fator(es) influenciam as consumidoras mães na realização dos mesversários, foram observados os seguintes itens: a motivação é um fator psicológico que move as escolhas da mãe de acordo com o momento que elas vivenciam naquele período, como o fato de comemorar o nascimento da criança, além da sua saúde, desenvolvimento mês-a-mês e as dificuldades de cada ciclo. A família e a influência exercida entram como um ponto crucial na realização dos mesversários, eles têm o maior vínculo com as mães e muitas vezes se envolvem com dicas, sugestões ou críticas, e também financeiramente. Assim, as mães os deixam se envolver e participar nas suas decisões para a realização dos mesversários.

Como contribuição, na área acadêmica, tendo em vista que ainda não é um tema bastante explorado, este estudo surge como uma oportunidade de outros autores, interessados pela temática, explorarem o seu conteúdo. Para o mercado, o trabalho traz informações que servem para o setor varejista, de eventos, de entretenimento, 


\section{FELIZ ANIVERSÁRIO(S): A INFLUÊNCIA NO COMPORTAMENTO DAS CONSUMIDORAS MÃES NA REALIZAÇÃO DOS MESVERSÁRIOS}

mostrando o que instiga as mães quando optam por investir nesse tipo de evento para os seus filhos, trazendo informações elucidativas para o campo mercadológico. Referente a sociedade, a pesquisa procura discutir como este evento vem se tornando muito mais presente no cotidiano das famílias, evidenciando como ela se origina e é vivenciada e sentida pelas famílias que as praticam.

No que se refere aos fatores limitadores, destaca-se as dificuldades na busca por informações referente ao tema, visto que ainda não é um tema muito abordado na área acadêmica. O cenário de isolamento social, derivado da COVID-19, impossibilitou a realização das entrevistas presenciais, conforme planejado no início do trabalho. Em decorrência disso, as entrevistas tiveram que ser digitais, construídas via Google Forms, e enviadas por e-mail e/ou WhatsApp.

Como sugestões de estudos futuros, recomenda-se que a pesquisa seja feita de forma quantitativa, para medir outras questões, outros constructos, como impactos, efeitos. Além disso, para avaliar a questão do(s) mesversário(s) de forma mais regional, é sugerido que a temática seja investigada em diferentes regiões do país, de forma mais concentrada, estabelecendo um comparativo entre as mães das diversas regiões do país. E, por fim, recomenda-se que a temática seja estudada à luz do contexto digital e como este ambiente influencia (ou não) no consumo deste fenômeno pelas mamães.

\section{REFERÊNCIAS}

ARNOLDI, M. A. G. C; ROSA, M. V. F. P. C. A entrevista na pesquisa qualitativamecanismos para validação dos resultados. 1. ed. - São Paulo: Autêntica, 2017.

ASSOCIAÇÃO BRASILEIRA DE EVENTOS (ABRAFESTA). Festas Infantis um mercado sem crises. Disponível em: https://abrafesta.com.br/clipping/item/508-festasinfantis-um-mercado-sem-crise Acesso em: 20 Fev. 2020.

BALDIN, N.; MUNHOZ, E. M. B. Snowball (bola de neve): uma técnica metodológica para pesquisa em educação ambiental comunitária. In: Congresso Nacional de Educação. 2011. p. 329-341.

BINOTTO, S., DENARDIN, E. S., MEDEIROS, F. S. B., BOLIGON, J. A. R.; MACHADO, F. F. Os fatores de influência no comportamento do consumidor: um estudo em uma cooperativa agrícola do RS. Revista de Gestão e Organizações Cooperativas, v. 1, n. 2, p. 13-26, 2014.

CARVAlHO, L. L.; SILVA, C. E. L.; BARROS, C. F. Uma análise da indústria do entretenimento sob a ótica do Desenvolvimento Sustentável. IX SEGeT-Simpósio de Excelência em Gestão e Tecnologia. Anais. 2012.

CASANELI, D. M. C. Confiança e desempenho organizacional: um estudo sobre a relação interorganizacional na prestação de serviço de festas infantis, 2009. Tese (PósGraduação) - Curso de Administração de empresas, Universidade Presbiteriana Mackenzie, São Paulo, 2009.

COBRA, M.; URDAN, A. T. Marketing básico. 5. ed. - São Paulo: Atlas, 2017.

ENGEL, J.; BLACKWELL, R; MINIARD, P. W.; Comportamento do consumidor. Rio de Janeiro: LTC-Livros Técnicos e Científicos Editora, 2000. 


\section{FELIZ ANIVERSÁRIO(S): A INFLUÊNCIA NO COMPORTAMENTO DAS CONSUMIDORAS MÃES NA REALIZAÇÃO DOS MESVERSÁRIOS}

FLICK, U. Introdução à pesquisa qualitativa (3a ed., J. E. Costa, Trad.). São Paulo: Artmed, 2009.

GIARETA, L. F. O comportamento do consumidor no processo de decisão de compra. Encontro Científico e Simpósio de Educação Unisalesiano, v. 3, p. 1-9, 2011.

LIMA, A. G. Fatores influenciadores no processo de decisão para contratação de serviços de decoração de festas infantis. 2019. TCC (Graduação) - Curso de Administração, Universidade Federal do Rio Grande do Norte, Natal, 2019.

MEDEIROS, E. A.; VARELA, S. B. L.; NUNES, J. B. C. Abordagem Qualitativa: estudo na pós-graduação em educação da Universidade Estadual do Ceará (2004-2014). Holos, v. 2, p. 174-189, 2017.

MENDES, T. R. O. Comportamento do consumidor, 2014. Tese (Doutorado) - Curso de Marketing e Comunicação, Escola Superior de Tecnologia e Gestão de Oliveira do Hospital Instituto Politécnico de Coimbra, Minas Gerais, 2014.

OLIVEIRA, M. M.; ABREU, N. R. PARABÉNS PRA VOCÊ!!! O CONSUMO DE MÃES EM FESTAS INFANTIS. Pensamento \& Realidade, v. 30, n. 2, 2015.

PORTAL G1. Mesversários. Disponível em: https://g1.globo.com/busca/?q=mesversario\&ps=on. Acesso em: 01 abr. 2020.

PORTAL EVENTOS. Mercado de festas e eventos cresce $14 \%$ ao ano e tem boas projeções $2019 . \quad$ Dara em: https://www.revistaeventos.com.br/EVENTOS/Mercado-de-festas-e-eventos-cresce-14ao-ano-e-tem-boas-projecoes-para-2019/47131. Acesso em: 01 abr. 2020.

ROCHA, E.; BARROS, C.; KARAM, K. Diversões perigosas: experiências de entretenimento e limites do consumo. In: ROCHA, E.; PEREIRA, C.; BARROS, C. (Orgs.). Cultura e experiência midiática. Rio de Janeiro: Mauad X: PUC-Rio, 2014.

SCHIFFMAN, L. G.; KANUK, L. L. Comportamento do consumidor. tradução. Reimpr.]. -Rio de Janeiro: LTC, 2015.

SECCO, C. F. C.; OlIVEIRA, E. M.; AMORIM, R. M. Comportamento do consumidor: fatores que determinam o processo de compra no mercado varejista em Palmas-TO. Revista Científica do ITPAC, v. 7, n. 3, p. 1-13, 2014.

SEGATA, J. B. " Mamães ativas": etnografia de um grupo mulheres, da gestação à maternidade. 2017. Dissertação de Mestrado - Curso de Antropologia Social, Universidade Federal do Rio Grande do Norte, Natal, 2017.

SILVA, I. C. A influência do marketing digital no comportamento do consumidor. 2019. TCC (Graduação) - Curso Superior de Tecnologia em Gestão Comercial, Instituto Federal da Paraíba, Guarabira, 2019.

SOlOMON, R. M. O Comportamento do Consumidor: Comprando, Possuindo e Sendo. 5. Ed. São Paulo: Bookman, 2016. 
TAVARES, F. Marketing: conceitos, tipos, objetivos e análise de desempenho. 2007. Disponível

em: <http://www.portaldomarketing.com.br/Artigos/Marketing_Conceitos_Tipos_Objetivos _e_analise_de_desempenho.htm>. Acesso em: 29 fev. 2020.

TEIXEIRA, J. C. I. Fatores que influenciam o comportamento do consumidor. AVM Instituto a Vez do Mestre. Rio de Janeiro, 2010.

VIEIRA, V. A. Comportamento do consumidor. Revista de Administração Contemporânea, v. 6, n. 3, p. 219-221, 2002. 